\title{
SR Research Square

\section{Surgical treatment of Temporal Lobe Epilepsy: comparative results of selective amygdalohippocampectomy versus anterior temporal lobectomy from a referral center in Brazil}

\author{
Laryssa C Azevedo Almeida \\ Santa Casa BH \\ Vanessa Alves Lobato \\ Santa Casa BH \\ Maria do Carmo Vasconcelos Santos \\ Santa Casa BH \\ Aline Curcio de Moraes \\ Santa Casa BH \\ Bruno Silva Costa ( $\square$ costabs@gmail.com ) \\ Santa Casa BH https://orcid.org/0000-0003-0780-4709
}

\section{Research Article}

Keywords: Temporal Lobe Epilepsy, Epilepsy Surgery, amygdalohippocampectomy, Mesial temporal sclerosis

Posted Date: September 20th, 2021

DOl: https://doi.org/10.21203/rs.3.rs-909392/v1

License: (c) (i) This work is licensed under a Creative Commons Attribution 4.0 International License. Read Full License 


\section{Abstract}

\section{Introduction}

Temporal Lobe Epilepsy (TLE) is a high prevalence neurological disorder and tends to drug refractoriness. Surgery has emerged as a promising treatment for managing crises and a better quality of life for these patients. The objective of this work is to compare the surgical results in terms of seizures control concerning the surgical technique performed (Anterior temporal lobectomy (ATL) vs. Selective amygdalohippocampectomy (SAH)) in a cohort of 132 patients operated in an epilepsy reference center.

\section{Materials and methods}

We performed a retrospective study based on the review of medical records of 146 patients operated for TLE from 2008 to 2019 at the Santa Casa de Misericordia in Belo Horizonte, Brazil. Initially, 13 patients were excluded from the study due to insufficient medical record data or follow-up loss. We used the ILAE (International League Against Epilepsy) scale to classify seizure control after surgery. We compared the surgical groups using the survival and Kaplan-Maier curves.

\section{Results}

A total of 132 patients were evaluated in this study, with a mean follow-up time after surgery of 57.2 months (12-137). In our data analysis, we found that the group of patients undergoing ATL had a higher prevalence of being completely seizure-free (ILAE I) $(57,1 \% \mathrm{vs.} 31 \%)$ and a higher rate of satisfactory seizure control $(88,6 \%$ vs. $69,3 \%) p=0.006$.

\section{Conclusion}

The literature is still controversial about seizure control results concerning the surgical technique used due to the lack of studies with a robust methodology for an adequate comparison. In our data analysis, we identified the superiority of ATL over SAH in seizure outcomes.

\section{Introduction}

Temporal lobe epilepsy (TLE) is the most common human epileptic syndrome[14], a disabling and progressive entity[3]. In addition to seizures, which already represent clinical management difficulties, they may also be associated with cognitive, language, or psychiatric disorders[7, 23]. A tendency to drug refractoriness characterizes it, and up to one-third of patients are drug-resistant[19]. In recent years, surgery has proven to be a therapeutic option with good results, already proven by a controlled clinical trial its superiority to drug treatment alone[27].

The etiology is multifactorial, with sclerosis of the hippocampus typically caused by inflammatory, infectious insults, trauma, or febrile seizures $[6,20]$. 
There are technical variations in TLE surgery, and there is no consensus on the best surgical approach. The most common techniques are Anterior temporal lobectomy (ATL) and selective amygdalohipocampectomy (SAH). Foerster pioneered subtotal temporal lobectomy in 1925[8]. Falconer developed en bloc resection of the temporal lobe and mesial structures in 1953[11]. Morris, in 1956 used the term standard temporal lobectomy for a $6.5 \mathrm{~cm}$ resection of the temporal lobe[15]. Spencer refined this technique with $4.5 \mathrm{~cm}$ in the non-dominant cortex and $3 \mathrm{~cm}$ in the dominant cortex[25]. Niemeyer, in 1958, described selective access to mesial temporal structures through an incision in the medial temporal lobe[17]. Wieser and Yasargil proposed a transsilvian approach to the amygdala and hippocampus[28].

There is still controversy about the best surgical approach for mesial temporal epilepsy[13].

Elseways, selective resections of mesial structures could have less cognitive effects, whereas an anterior temporal lobectomy would improve seizure control.

In a review in 2008, Schramm[22] cites eight studies that compared selective surgery against temporal lobectomy concerning seizure control.

In six of these studies, the authors found no difference in seizure control despite the surgical approach used. In two, 1 in children[2, 4], ATL was more effective.

Josephson[12]compared ATL and SAH in a meta-analysis that included 13 articles and a total of 1203 patients, showing better control of seizures in ATL.

\section{Objective}

This study aims to compare the two surgical techniques (ATL vs. SAH) regarding seizure control.

\section{Materials And Methods}

A retrospective study was carried out based on the medical records of 146 patients operated on for temporal lobe epilepsy from 2008 to 2019. The ILAE classification (Table 1) was used to determine the degree of seizure control, and we compared the descriptive results according to the technique used.

The preoperative evaluation of these patients included neuropsychological testing, video-EEG, and highresolution MRI. In cases where the video-EEG with scalp electrodes failed to define the temporal lobe as an epileptogenic source, a foramen ovale electrode was implanted as a complementary method. We included only patients with unilateral hippocampal sclerosis on MRI and concordant epileptic onset on video-EEG.

The same surgeon performed all surgeries. In right-sided hippocampal sclerosis, a temporal lobectomy was performed using the Spencer technique[25]. In left hippocampal sclerosis, a selective amygdalo hippocampectomy was used as described by Niemeyer[17]. 
We compared the two groups using contingency tables. We used analysis of variance (ANOVA) to compare the results with the kind of surgery (ATL or SAH) and also performed a Kaplan-Meier survival analysis until the "seizure" event, ILAE 1 status, and a good result (ILAE 1 to 3 ). The data were analyzed with the IBM SPSS Statistics Software. A p-value of less than 0.05 was considered significant.

\section{Results}

Our database computed 146 patients operated for temporal lobe epilepsy, secondary to hippocampal sclerosis, between 2008 and 2019. 13 were excluded from the study in our initial analysis due to incomplete medical records or follow-up loss. One patient died in the immediate postoperative period from pulmonary thromboembolism (mortality of $0.07 \%$ ) and was excluded from the analysis. The remaining 132 patients were included in the evaluation. Seventy-two patients were female (53\%) and 60 male $(47 \%)$. The mean age at the time of surgery was 37.85 years (9-65 years).

On $70(53 \%)$ patients, we had hippocampal sclerosis on the right and $62(47 \%)$ left-sided hippocampal sclerosis.

The mean follow-up time after surgery was 57.2 months (12-137).

Sixty-six (50\%) patients had at least one seizure in the follow-up period (events in the first 30 days after surgery were not considered).

At the end of the follow-up period, 105 (79.5\%) patients were on ILAE 1 to 3 (good result). Of the patients submitted to ATL, 62 (88.6\%) obtained a good result against $43(69.3 \%)$ of the patients in the SAH group $(p=0.006)$

In our series, only $58(43.9 \%)$ patients were on ILAE 1 at the end of the follow-up period, $40(57.1 \%)$ in the ATL group, and $18(31.0 \%)$ in the SAH group $(p=0.001)$. table 2

The average interval until an epileptic event was 22.8 months (ranging from 1 to 86.1 months). Patients undergoing ATL had a mean time to the first seizure of 23.04 months against 21.86 in those undergoing $\mathrm{SAH}$, with no statistical difference $(\mathrm{p}=0.82)$. Fig 1 .

The Kaplan Meyer mortality curves (Fig 2), using the Log Rank (Mantel-Cox) statistical analysis, with seizure as the event, showed a significant difference between the ATL and SAH $(p=0.024)$

\section{Discussion}

The primary purpose of surgery is to control seizures. Maintaining a good functional status of patients is also mandatory. The search for a more selective resection is based on not worsening memory and language deficits, especially in the dominant hemisphere. It has been shown in several articles that the selective resection of mesial structures has a benefit, even if marginal, in the cognitive assessment of patients $[5,9,21]$. Other authors do not show differences between ATL and SAH regarding 
neuropsychological prognosis[16, 29]. Helmstaedter[10] postulates that the cognitive deficit after eloquent temporal resection could be more linked to perioperative cortical injury, visible in post-surgical MRI, than the resection type.

Concerning the control of epilepsy, there are variable results in the literature when comparing SAH and ATL. Several authors show equality in seizure control $[1,18,26]$, while others show better results in ATL[2, 4].

Clusmann \{Clusmann: 2004fo\} in a series of 89 children and adolescents found a worse result in seizure control in SAH when compared to ATL. Also, patients with left hippocampal sclerosis had a worse result despite the surgical technique.

In a meta-analysis including 13 studies and 1203 patients, Josephson[12] found better control of seizures in ATL than SAH.

In our series, we performed SAH in left HS and ATL in right HS. For this reason, there is no way to compare the techniques as to the outcome in language and memory since all surgeries in the dominant hemisphere were SAH.

In the Author's opinion, we found no technical difficulties related to the type of surgery. Both being performed with the same degree of difficulty.

We sought to compare the two types of surgery in terms of good surgical outcomes and the occurrence of seizures, and the complete control of seizures (ILAE 1).

The ANOVA statistical analysis show a better outcome in occurrence of seizures $(p=0.005)$, ILAE 1 final result $(p=0.001)$ and good result $(p=0.006)$ in favour of ATL.

We performed Kaplan Meyer's survival analysis having a seizure as the target event. The curves showed better results in ATL over SAH. The Log Rank statistical analysis shows a significant difference favoring the ATL group $(p=0.029)$.

The Kaplan Meier graphs show a downward curve with a progressive worsening of the results over time, consistent with the findings described in the literature.

The results are consistent with a better surgical prognosis in resections that include the temporal neocortex over more selective resections.

Interestingly, the interval until the first epileptic event was similar when comparing the two groups. However, patients in the SAH group had crises more often after this initial event (chart 1). this finding could be related to the maintenance of an altered neuronal network in patients with more selective resection, which quickly resumes the pattern of seizures after a first ictal event[24]. 


\section{Limitations Of The Study}

We did not assess neuropsychological, speech, and language differences between groups, as all surgeries in the dominant hemisphere were $\mathrm{SAH}$

It is essential to mention that Clusmann[4], in 2004, observed that surgeries in the dominant hemisphere had worse results despite the technique used. It is a possible bias in our work.

We tried to exclude all patients who had MRI lesions other than HS to avoid a worse result in selective surgeries for patients who had lesions in the temporal neocortex. However, MRI is not always able to clearly show small dysplastic lesions.

The time of postoperative evaluation was long enough to show the differences between the two techniques. As there is a tendency for the results to progressively worsen over time, as demonstrated in our survival curves, a longer follow-up perhaps showed that the two techniques tend to match up with a longer follow-up.

\section{Conclusion}

The literature is still controversial about seizure control results concerning the surgical technique used due to the lack of studies with a robust methodology for an adequate comparison. In our data analysis, we identified the superiority of ATL over SAH in seizure outcomes.

\section{Declarations}

Funding: The Author (s) received no financial support for the research, authorship, and/or publication of this article.

Conflicts of interest: The authors certify that they have NO affiliations with or involvement in any organization or entity with any financial interest (such as honoraria; educational grants; participation in speakers' bureaus; membership, employment, consultancies, stock ownership, or other equity interest; and expert testimony or patent-licensing arrangements), or non-financial interest (such as personal or professional relationships, affiliations, knowledge or beliefs) in the subject matter or materials discussed in this manuscript.

Availability of data and material: All relevant data are included in the manuscript. Additional data and information will be provided from the corresponding Author upon reasonable request.

Code availability: Not applicable.

Ethics approval: The national ethics board approved the study (CAAE number 01364012.9.0000.5149). 
Consent to participate: All patients signed informed consent, and the study was conducted following the Declaration of Helsinki.

Consent to publication: Not applicable.

\section{References}

1. Arruda F, Cendes F, Andermann F, Dubeau F, Villemure J-G, Jones-Gotman M, Poulin N, Arnold DL, Olivier A (1996) Mesial atrophy and outcome after amygdalohippocampectomy or temporal lobe removal. Ann Neurol 40:446-450. doi:10.1002/ana.410400314

2. Bate $H$, Eldridge P, Varma T, Wieshmann UC (2007) The seizure outcome after amygdalohippocampectomy and temporal lobectomy. Eur J Neurol 14:90-94. doi:10.1111/j.14681331.2006.01565.x

3. Cascino GD (2009) Temporal lobe epilepsy is a progressive neurologic disorder: Time means neurons! Neurology 72:1718-1719. doi:10.1212/WNL.0b013e3181a4e465

4. Clusmann H, Kral T, Gleissner U, Sassen R, Urbach H, Blümcke I, Bogucki J, Schramm J (2004) Analysis of Different Types of Resection for Pediatric Patients with Temporal Lobe Epilepsy. Neurosurgery 54:847-860. doi:10.1227/01.NEU.0000114141.37640.37

5. Clusmann H, Schramm J, Kral T, Helmstaedter C, Ostertun B, Fimmers R, Haun D, Elger CE (2002) Prognostic factors and outcome after different types of resection for temporal lobe epilepsy. $\mathrm{J}$ Neurosurg 97:1131-1141. doi:10.3171/jns.2002.97.5.1131

6. Costa BS, Santos MCV, Rosa DV, Schütze M, Miranda DM, Romano-Silva MA (2019) Automated evaluation of hippocampal subfields volumes in mesial temporal lobe epilepsy and its relationship to the surgical outcome. Epilepsy Res 154:152-156. doi:10.1016/j.eplepsyres.2019.05.011

7. Engel J Jr, Pedley TA (2008) Epilepsy: A Comprehensive Textbook, 2nd edn. Lippincott Williams \& Wilkins, Philadelphia

8. Feindel W, Leblanc R, de Almeida AN (2009) Epilepsy Surgery: Historical Highlights 1909-2009. Epilepsia 50:131-151. doi:10.1111/j.1528-1167.2009.02043.x

9. Helmstaedter C, Reuber M, Elger CCE (2002) Interaction of cognitive aging and memory deficits related to epilepsy surgery. Ann Neurol 52:89-94. doi:10.1002/ana.10260

10. Helmstaedter C, Van Roost D, Clusmann H, Urbach H, Elger CE, Schramm J (2004) Collateral brain damage, a potential source of cognitive impairment after selective surgery for control of mesial temporal lobe epilepsy. J Neurol Neurosurg Psychiatr 75:323-326. doi:10.1136/jnnp.2003.013706

11. Hill D, Falconer MA, Pampiglione G, Liddell DW (1953) Discussion on the surgery of temporal lobe epilepsy. Proc R Soc Med 46:965-976

12. Josephson CB, Dykeman J, Fiest KM, Liu X, Sadler RM, Jette N, Wiebe S (2013) Systematic review and meta-analysis of standard vs selective temporal lobe epilepsy surgery. Neurology 80:16691676. doi:10.1212/WNL.0b013e3182904f82 
13. Mansouri A, Fallah A, McAndrews MP, Cohn M, Mayor D, Andrade D, Carlen P, del Campo JM, Tai P, Wennberg RA, Valiante TA (2014) Neurocognitive and Seizure Outcomes of Selective Amygdalohippocampectomy versus Anterior Temporal Lobectomy for Mesial Temporal Lobe Epilepsy. Epilepsy Research Treatment. doi:10.1155/2014/306382

14. Mohan M, Keller S, Nicolson A, Biswas S, Smith D, Osman Farah J, Eldridge P, Wieshmann U (2018) The long-term outcomes of epilepsy surgery. PLoS ONE 13:e0196274. doi:10.1371/journal.pone.0196274

15. Morris AA (1956) Temporal lobectomy with removal of uncus, hippocampus, and amygdala; results for psychomotor epilepsy three to nine years after operation. AMA Arch Neurol Psychiatry 76:479496. doi:10.1001/archneurpsyc. 1956.02330290023003

16. Nascimento FA, Gatto LAM, Silvado C, Mäder-Joaquim MJ, Moro MS, Araujo JC (2016) Anterior temporal lobectomy versus selective amygdalohippocampectomy in patients with mesial temporal lobe epilepsy. Arq Neuropsiquiatr 74:35-43. doi:10.1590/0004-282X20150188

17. Niemeyer $P$ (1958) The transventricular amygdalohippocampectomy in temporal lobe epilepsy. In: Baldwin M, Bailey P (eds) Temporal Lobe Epilepsy. Charles C Thomas, Springfield, pp 461-482

18. Paglioli E, Palmini A, Portuguez M, Paglioli E, Azambuja N, da Costa JC, da Silva Filho HF, Martinez JV, Hoeffel JR (2006) Seizure and memory outcome following temporal lobe surgery: selective compared with nonselective approaches for hippocampal sclerosis. J Neurosurg 104:70-78. doi:10.3171/jns.2006.104.1.70

19. Querol Pascual MR (2007) Temporal Lobe Epilepsy: Clinical Semiology and Neurophysiological Studies. Seminars in Ultrasound. CT MRI 28:416-423. doi:10.1053/j.sult.2007.09.004

20. Rosa DV, Rezende VB, Costa BS, Mudado F, Schütze M, Torres KC, Martins LC, Moreira-Filho CA, Miranda DM, Romano-Silva MA (2016) Circulating CD4 and CD8 T cells expressing pro-inflammatory cytokines in a cohort of mesial temporal lobe epilepsy patients with hippocampal sclerosis. Epilepsy Res 120:1-6. doi:10.1016/j.eplepsyres.2015.11.011

21. Rydenhag B, Silander HC (2001) Complications of epilepsy surgery after 654 procedures in Sweden, September 1990-1995: a multicenter study based on the Swedish National Epilepsy Surgery Register. Neurosurgery 49:51-56. doi:10.1097/00006123-200107000-00007 discussion 56-7.

22. Schramm J, Clusmann H (2008) The surgery of epilepsy. Neurosurgery 62 Suppl 2:463-481. doi:10.1227/01.neu.0000316250.69898.23 discussion 481.

23. Shahani L, Cervenka $G$ (2019) Impact of surgical intervention on seizure and psychiatric symptoms in patients with temporal lobe epilepsy. BMJ Case Rep 12:e229242-e229243. doi:10.1136/bcr-2019229242

24. Sinha N, Wang Y, Moreira da Silva N, Miserocchi A, Mcevoy AW, de Tisi J, Vos SB, Winston GP, Duncan JS, Taylor PN (2021) Structural Brain Network Abnormalities and the Probability of Seizure Recurrence After Epilepsy Surgery. Neurology 96:e758-e771. doi:10.1212/WNL.0000000000011315

25. Spencer DD, Spencer SS, Mattson RH, Williamson PD, Novelly RA (1984) Access to the posterior medial temporal lobe structures in the surgical treatment of temporal lobe epilepsy. Neurosurgery 
15:667-671. doi:10.1227/00006123-198411000-00005

26. Tanriverdi T, Olivier A Cognitive changes after unilateral cortico-amygdalohippocampectomy unilateral selective-amygdalohippocampectomy mesial temporal lobe epilepsy. Turkish Neurosurgery 17:91-99

27. Wiebe S, Blume WT, Girvin JP, Eliasziw M, Effectiveness, Efficiency of Surgery for Temporal Lobe Epilepsy Study Group (2001) A randomized, controlled trial of surgery for temporal-lobe epilepsy. N Engl J Med 345:311-318. doi:10.1056/NEJM200108023450501

28. Wieser HG, Yaşargil MG (1982) Selective amygdalohippocampectomy as a surgical treatment of mesiobasal limbic epilepsy. Surg Neurol 17:445-457. doi:10.1016/s0090-3019(82)80016-5

29. Wolf RL, Ivnik RJ, Hirschorn KA, Sharbrough FW, Cascino GD, Marsh WR (1993) Neurocognitive efficiency following left temporal lobectomy: standard versus limited resection. J Neurosurg 79:7683. doi:10.3171/jns.1993.79.1.0076

\section{Tables}

Table 1. ILAE outcome classification (from Wieser HG, Blume WT, Fish D, Goldensohn E, Hufnagel A, King D, et al. ILAE Commission Report. Proposal for a new classification of outcome with respect to epileptic seizures following epilepsy surgery. 2001. pp. 282-6).

\begin{tabular}{|ll|}
\hline $\begin{array}{l}\text { Outcome } \\
\text { classification }\end{array}$ & Definition \\
\hline 1 & Completely seizure free; no auras \\
\hline 2 & Only auras; no other seizures \\
\hline 3 & One to three seizure days per year; \pm auras \\
\hline 5 & Four seizure days per year to $50 \%$ reduction of baseline seizure days; \pm auras \\
\hline 6 & $\begin{array}{l}\text { Less than } 50 \% \text { reduction of baseline seizure days to } 100 \% \text { increase of baseline } \\
\text { seizure days; } \pm \text { auras }\end{array}$ \\
\hline
\end{tabular}

Table 2: Frequencies comparing anterior temporal lobectomy (ATL) and selective amygdalo hippocampectomy (SAH) groups. 


\begin{tabular}{|c|c|c|c|c|c|}
\hline & & Total & ATL & SAH & $\mathbf{p}$ \\
\hline & & & Right HS & Left HS & \\
\hline $\mathbf{n}$ & & 132 & $70(53.0 \%)$ & $62(47.0 \%)$ & \\
\hline \multirow[t]{2}{*}{ Gender } & M & $60(47.0 \%)$ & $30(42.9 \%)$ & $30(48.4 \%)$ & \\
\hline & $\mathrm{F}$ & $72(53.0 \%)$ & $40(57.1 \%)$ & $32(51.6 \%)$ & \\
\hline Mean age in years & & 37,85 & 36,94 & 38,87 & \\
\hline Mean Follow up in months & & 57.2 & 55,7 & 58,8 & \\
\hline \multirow[t]{7}{*}{ ILAE } & 1 & $58(43.9 \%)$ & $40(57.1 \%)$ & $18(31.0 \%)$ & $P=0.001$ \\
\hline & 2 & $2(1,5 \%)$ & $0(0.0 \%)$ & $2(3.2 \%)$ & \\
\hline & 3 & $45(34.1 \%)$ & $22(31.4 \%)$ & $23(37.1 \%)$ & \\
\hline & 1 to 3 & 105 (79.5\%) & $62(88.6 \%)$ & $43(69.3 \%)$ & $P=0.006$ \\
\hline & 4 & $16(12.1 \%)$ & $5(7.1 \%)$ & $11(17.7 \%)$ & \\
\hline & 5 & $11(8.3 \%)$ & $3(4.3 \%)$ & $8(12.9 \%)$ & \\
\hline & 6 & $0(0.0 \%)$ & $0(0.0 \%)$ & $0(0.0 \%)$ & \\
\hline
\end{tabular}

ILAE 1 to 3 are considered as good result.

Figures 


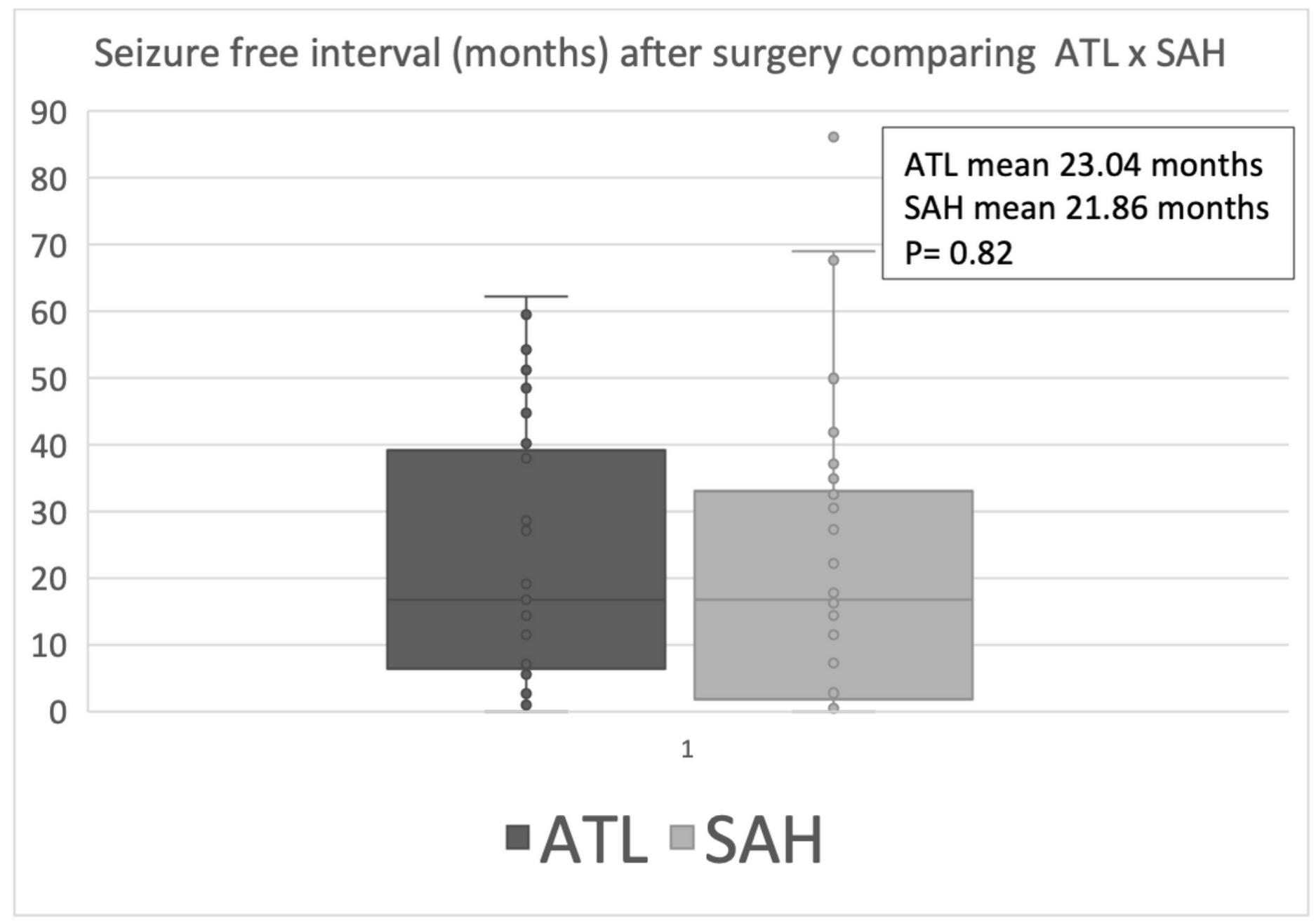

Figure 1

Caption not included with this version. 


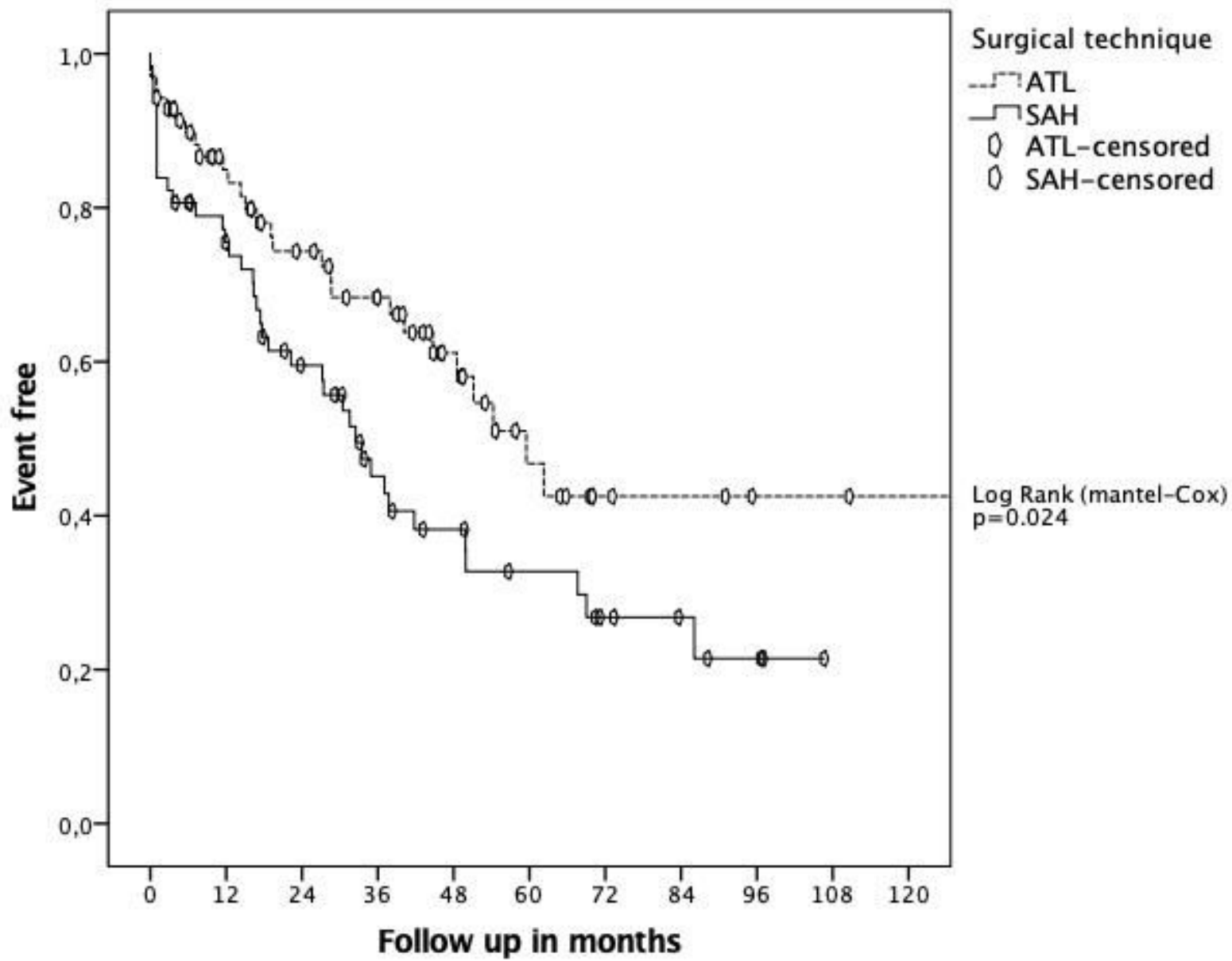

Figure 2

Caption not included with this version. 